\title{
Ulam-Hyers Stability and Well-Posedness of Fixed Point Problems for $\alpha$ - $\lambda$-Contraction Mapping in Metric Spaces
}

\author{
Marwan Amin Kutbi ${ }^{1}$ and Wutiphol Sintunavarat ${ }^{2}$ \\ ${ }^{1}$ Department of Mathematics, King Abdulaziz University, P.O. Box 80203, Jeddah 21589, Saudi Arabia \\ ${ }^{2}$ Department of Mathematics and Statistics, Faculty of Science and Technology, Thammasat University, \\ Rangsit Center, Pathum Thani 12121, Thailand
}

Correspondence should be addressed to Wutiphol Sintunavarat; wutiphol@mathstat.sci.tu.ac.th Received 13 January 2014; Revised 27 April 2014; Accepted 22 May 2014; Published 12 June 2014

Academic Editor: Adrian Petrusel

Copyright ( 2014 M. A. Kutbi and W. Sintunavarat. This is an open access article distributed under the Creative Commons Attribution License, which permits unrestricted use, distribution, and reproduction in any medium, provided the original work is properly cited.

We study Ulam-Hyers stability and the well-posedness of the fixed point problem for new type of generalized contraction mapping, so called $\alpha$ - $\lambda$-contraction mapping. The results in this paper generalize and unify several results in the literature such as the Banach contraction principle.

\section{Introduction and Preliminaries}

In 1940, the stability problem of functional equations, first initial from a question of Ulam. Among those was the following question concerning the stability of group homomorphisms [1].

Question 1. Let $G_{1}$ be a group and let $G_{2}$ be a metric group with a metric $d: G_{2} \times G_{2} \rightarrow[0, \infty)$. Given $\epsilon>0$, does there exist a $\delta>0$ such that if a function $h: G_{1} \rightarrow G_{2}$ satisfies the inequality

$$
d(h(x y), h(x) h(y))<\delta,
$$

for all $x, y \in G_{1}$, then there is a homomorphism $H: G_{1} \rightarrow$ $G_{2}$ with

$$
d(h(x), H(x))<\epsilon,
$$

for all $x \in G_{1}$ ?

If the answer of this equation is affirmative, we say that the functional equation for group homomorphism is stable.

Next year, some partial answer of Ulam's question about Banach spaces was first given by Hyers [2] which opened an avenue for further development of analysis in this field.
Theorem 1 (see [2]). Let $E_{1}, E_{2}$ be two Banach spaces and let $f: E_{1} \rightarrow E_{2}$ be a function such that

$$
\|f(x+y)-f(x)-f(y)\| \leq \delta,
$$

for some $\delta>0$ and for all $x, y \in E_{1}$. Then the limit

$$
A(x):=\lim _{n \rightarrow \infty} 2^{-n} f\left(2^{n} x\right)
$$

exists for each $x \in E_{1}$, and $A: E_{1} \rightarrow E_{2}$ is the unique additive function such that

$$
\|f(x)-A(x)\| \leq \delta,
$$

for all $x \in E_{1}$. Moreover, if $f(t x)$ is continuous in $t$ for each fixed $x \in E_{1}$, then the function $A$ is linear.

Taking this result into consideration, the additive Cauchy equation $f(x+y)=f(x)+f(y)$ is said to have the UlamHyers stability on $\left(E_{1}, E_{2}\right)$ if, for each function $f: E_{1} \rightarrow E_{2}$ satisfying inequality (3) for some $\delta \geq 0$ and for all $x, y \in E_{1}$, there exists an additive function $A: E_{1} \rightarrow E_{2}$ such that $f-A$ is bounded on $E_{1}$.

There are a number of results studied and extended Ulam-Hyers stability in many directions. In particular, UlamHyers stability for fixed point problems has been studied by 
many researchers such as Bota et al. [3], Bota-Boriceanu and Petruşel [4], Lazăr [5], Rus [6, 7], and F. A. Tişe and I. C. Tişe [8]. Furthermore, there are several remarkable results on the stability of certain classes of functional equations via fixed point approach. Some interesting results in this direction are presented by several mathematicians such as Brzdęk et al. [9], Brzdek and Ciepliski [10], Brzdęk and Ciepliński [11], and Cadariu et al. [12].

On the other hand, the concept of well-posedness of a fixed point problem has been of great interest to several researchers, for example, de Blasi and Myjak [13], Reich and Zaslavski [14], Lahiri and Das [15], and Popa [16, 17].

Recently, Samet et al. [18] introduced the concept of $\alpha$ admissible mapping as follows.

Definition 2 (see [18]). Let $X$ be a nonempty set and let $\alpha$ : $X \times X \rightarrow[0, \infty)$ be a mapping. A mapping $T: X \rightarrow X$ is said to be $\alpha$-admissible if it satisfies the following condition:

$$
\text { for } x, y \in X \quad \text { for which } \alpha(x, y) \geq 1 \Longrightarrow \alpha(T x, T y) \geq 1 \text {. }
$$

Example 3. Let $X=(0, \infty)$. Define $T: X \rightarrow X$ and $\alpha$ : $X \times X \rightarrow[0, \infty)$ by $T x=\ln (x+1)$ for all $x \in X$ and

$$
\alpha(x, y)= \begin{cases}\pi-\lfloor\sin x+\cos y\rfloor & \text { if } x \geq y, \\ \frac{1}{1+x+y} & \text { if } x<y .\end{cases}
$$

Then, $T$ is $\alpha$-admissible.

Example 4. Let $X=[1, \infty)$. Define $T: X \rightarrow X$ and $\alpha$ : $X \times X \rightarrow[0, \infty)$ by $T x=x^{2}+x+2$ for all $x \in X$ and

$$
\alpha(x, y)= \begin{cases}x^{2}+y^{2} & \text { if } x \geq y \\ 0 & \text { if } x<y .\end{cases}
$$

Then, $T$ is $\alpha$-admissible.

Remark 5. In the setting of Examples 3 and 4 every nondecreasing self-mapping $T$ is $\alpha$-admissible.

They also introduced the new type of extension of Banach contraction and proved a fixed point theorem for such mapping via the concept of $\alpha$-admissible mapping. As application, they showed that these results can be utilized to derive fixed point theorems in partially ordered spaces. Furthermore, they apply the main results to the ordinary differential equations. Subsequently, there are a number of results proved for generalized contraction mappings via the concept of $\alpha$-admissible mapping in metric spaces and other spaces (see [19-26] and references therein).

With this work we have two purposes. The first aim of this work is to present new type of contraction mapping. We also establish some existence and uniqueness of fixed point theorems for such mappings in metric spaces via the concept of $\alpha$-admissible mapping. Our second purpose is to present Ulam-Hyers stability and well-posedness of a fixed point problem for this mapping in metric spaces.

\section{Main Results}

For nonempty set $X$ and self-mapping $f: X \rightarrow X$, let $\Lambda_{f}$ be the class of functions $\lambda: X \rightarrow[0,1)$ for which $\lambda(f(x)) \leq$ $\lambda(x)$ for all $x \in X$.

First we give the following definition as a generalization of Banach contraction mappings.

Definition 6. Let $(X, d)$ be a metric space and let $f: X \rightarrow X$ be a given mapping. One says that $f$ is an $\alpha$ - $\lambda$-contraction mapping if there exist two functions $\alpha: X \times X \rightarrow[0, \infty)$ and $\lambda \in \Lambda_{f}$ such that

$$
\alpha(x, y) d(f(x), f(y)) \leq \lambda(x) d(x, y), \quad \forall x, y \in X .
$$

Remark 7. It is easy to check that an $\alpha$ - $\lambda$-contraction mapping is reduced to a Banach contraction mapping if $\alpha(x, y)=1$ for all $x, y \in X$ and $\lambda(x)=k$ for all $x \in X$, where $k \in[0,1)$.

Now, we give some examples which show that the concept of an $\alpha$ - $\lambda$-contraction mapping is real generalization of Banach contraction mapping.

Example 8. Let $X=[0, \infty)$, and the metric $d: X \times X \rightarrow$ $[0, \infty)$ is defined by

$$
d(x, y)=|x-y|
$$

for all $x, y \in X$. Define $f: X \rightarrow X$ and $\alpha: X \times X \rightarrow[0, \infty)$ by

$$
\begin{gathered}
f(x)= \begin{cases}\frac{x}{3}, & x \in[0,1], \\
5 x, & x>1,\end{cases} \\
\alpha(x, y)= \begin{cases}2, & x, y \in[0,1], \\
0, & \text { otherwise. }\end{cases}
\end{gathered}
$$

We obtain that

$$
d(f(2), f(3))=d(10,15)=5>1=d(2,3) .
$$

Therefore, $f$ is not a Banach contraction. It is easy to see that $f$ is an $\alpha$ - $\lambda$-contraction mapping, where $\lambda: X \rightarrow[0,1)$ is defined by $\lambda(x)=2 / 3$ for all $x \in X$.

Next, we give nontrivial example of an $\alpha$ - $\lambda$-contraction mapping.

Example 9. Let $X=[0,1]$, and the metric $d: X \times X \rightarrow$ $[0, \infty)$ is defined by

$$
d(x, y)=|x-y|
$$

for all $x, y \in X$. Define $f: X \rightarrow X$ and $\alpha: X \times X \rightarrow[0, \infty)$ by

$$
\begin{gathered}
f(x)= \begin{cases}\frac{x^{2}}{2}, & x \in[0,1), \\
1, & x=1,\end{cases} \\
\alpha(x, y)= \begin{cases}1, & x, y \in[0,1), \\
0, & \text { otherwise. }\end{cases}
\end{gathered}
$$


We obtain that

$$
d\left(f\left(\frac{1}{2}\right), f(1)\right)=d\left(\frac{1}{8}, 1\right)=\frac{7}{8}>\frac{1}{2}=d\left(\frac{1}{2}, 1\right) .
$$

This implies that $f$ is not a Banach contraction. Next, we show that $f$ is an $\alpha$ - $\lambda$-contraction mapping, where $\lambda: X \rightarrow[0,1)$ is defined by

$$
\lambda(x)= \begin{cases}\frac{x+1}{2}, & x \in[0,1) \\ \frac{2}{3}, & x=1 .\end{cases}
$$

Firstly, we show that $\lambda \in \Lambda_{f}$. For $x \in[0,1)$, we get

$$
\begin{aligned}
\lambda(f(x)) & =\lambda\left(\frac{x^{2}}{2}\right) \\
& =\frac{1}{2}\left(\frac{x^{2}}{2}+1\right) \\
& =\frac{x^{2}}{4}+\frac{1}{2} \leq \frac{x^{2}}{2}+\frac{1}{2} \\
& \leq \frac{x+1}{2} \leq \lambda(x) .
\end{aligned}
$$

Also, we get

$$
\lambda(f(1))=\lambda(1)=\frac{2}{3}=\lambda(1) .
$$

From (17) and (18), we conclude that $\lambda \in \Lambda_{f}$.

Secondarily, we claim that inequality (9) holds. For $x, y \in$ $[0,1)$, we have

$$
\begin{aligned}
\alpha(x, y) d(f(x), f(y)) & =\left|\frac{x^{2}-y^{2}}{2}\right| \\
& =\left(\frac{|x+y|}{2}\right)|x-y| \\
& \leq\left(\frac{x+1}{2}\right)|x-y| \\
& =\lambda(x) d(x, y) .
\end{aligned}
$$

Otherwise, we see that inequality (9) holds. Therefore, $f$ is an $\alpha$ - $\lambda$-contraction mapping.

Our first main result is the following.

Theorem 10. Let $(X, d)$ be a complete metric space and let $f: X \rightarrow X$ be an $\alpha$ - $\lambda$-contraction mapping satisfying the following conditions:

(i) $f$ is $\alpha$-admissible;

(ii) there exists $x_{0} \in X$ such that $\alpha\left(x_{0}, f\left(x_{0}\right)\right) \geq 1$;

(iii) $f$ is continuous.

Then the fixed point problem of $f$ has a solution; that is, there exists $x^{*} \in X$ such that $x^{*}=f\left(x^{*}\right)$.
Proof. Let $x_{0} \in X$ such that $\alpha\left(x_{0}, f\left(x_{0}\right)\right) \geq 1$ (such a point exists from condition (ii)). Define the sequence $\left\{x_{n}\right\}$ in $X$ by

$$
x_{n}=f\left(x_{n-1}\right), \quad \forall n \in \mathbb{N} .
$$

If $x_{n}=x_{n-1}$ for some $n \in \mathbb{N}$, then $x^{*}=x_{n}$ is a fixed point for $f$ and the proof finishes. Therefore, we may assume that

$$
x_{n} \neq x_{n-1} \quad \forall n \in \mathbb{N} \text {. }
$$

Since $f$ is $\alpha$-admissible and $\alpha\left(x_{0}, x_{1}\right)=\alpha\left(x_{0}, f\left(x_{0}\right)\right) \geq 1$, we get $\alpha\left(f\left(x_{0}\right), f\left(x_{1}\right)\right)=\alpha\left(x_{1}, x_{2}\right) \geq 1$. By induction, we get

$$
\alpha\left(x_{n-1}, x_{n}\right) \geq 1, \quad \forall n \in \mathbb{N} \text {. }
$$

Applying inequality (9) with $x=x_{0}$ and $y=x_{1}$ and using (22), we have

$$
\begin{aligned}
d\left(x_{1}, x_{2}\right) & =d\left(f\left(x_{0}\right), f\left(x_{1}\right)\right) \\
& \leq \alpha\left(x_{0}, x_{1}\right) d\left(f\left(x_{0}\right), f\left(x_{1}\right)\right) \\
& \leq \lambda\left(x_{0}\right) d\left(x_{0}, x_{1}\right) .
\end{aligned}
$$

Again, applying inequality (9) with $x=x_{1}$ and $y=x_{2}$ and using (22) and the property of function $\lambda$, we get

$$
\begin{aligned}
d\left(x_{2}, x_{3}\right) & =d\left(f\left(x_{1}\right), f\left(x_{2}\right)\right) \\
& \leq \alpha\left(x_{1}, x_{2}\right) d\left(f\left(x_{1}\right), f\left(x_{2}\right)\right) \\
& \leq \lambda\left(x_{1}\right) d\left(x_{1}, x_{2}\right) \\
& =\lambda\left(f\left(x_{0}\right)\right) d\left(x_{1}, x_{2}\right) \\
& \leq \lambda\left(x_{0}\right) d\left(x_{1}, x_{2}\right) \\
& \leq\left[\lambda\left(x_{0}\right)\right]^{2} d\left(x_{0}, x_{1}\right) .
\end{aligned}
$$

By the same procedure, we get

$$
d\left(x_{n}, x_{n+1}\right) \leq\left[\lambda\left(x_{0}\right)\right]^{n} d\left(x_{0}, x_{1}\right), \quad \forall n \in \mathbb{N} .
$$

Since $\lambda\left(x_{0}\right) \in[0,1)$, we obtain that $\left\{x_{n}\right\}$ is a Cauchy sequence in metric spaces $X$. By the completeness of $X$, we get $\lim _{n \rightarrow \infty} x_{n}=x^{*}$ for some $x^{*} \in X$. Since $f$ is continuous,

$$
x^{*}=\lim _{n \rightarrow \infty} x_{n+1}=\lim _{n \rightarrow \infty} f\left(x_{n}\right)=f\left(\lim _{n \rightarrow \infty} x_{n}\right)=f\left(x^{*}\right) ;
$$

that is, $x^{*}$ is a fixed point of $f$ and thus the fixed point problem of $f$ has a solution. This completes the proof.

Example 11. Let $X=[0, \infty)$, and the metric $d: X \times X \rightarrow$ $[0, \infty)$ is defined by

$$
d(x, y)=|x-y|
$$

for all $x, y \in X$. Define $f: X \rightarrow X$ and $\alpha: X \times X \rightarrow[0, \infty)$ by

$$
\begin{aligned}
& f(x)= \begin{cases}\frac{x}{2}, & x \in[0,1], \\
\frac{5 x-3}{4}, & x>1,\end{cases} \\
& \alpha(x, y)= \begin{cases}1, & x, y \in[0,1] \\
0, & \text { otherwise. }\end{cases}
\end{aligned}
$$


We observe that $f$ is an $\alpha$ - $\lambda$-contraction mapping, where $\lambda$ : $X \rightarrow[0,1)$ is defined by $\lambda(x)=1 / 2$ for all $x \in X$. Also, $f$ is $\alpha$-admissible and continuous. It is easy to see that there exist $x_{0}=1 \in X$ such that $\alpha\left(x_{0}, f\left(x_{0}\right)\right)=\alpha(1, f(1))=\alpha(1,1 / 2)=$ 1 . Therefore, all hypotheses of Theorem 10 hold. Then we can apply Theorem 10. Indeed, the fixed points of $f$ are 0 and 3.

In the following theorem, we will omit the continuity hypothesis of $f$ by adding a new condition.

Theorem 12. Let $(X, d)$ be a complete metric space and let $f: X \rightarrow X$ be an $\alpha$ - $\lambda$-contraction mapping satisfying the following conditions:

\section{(i) $f$ is $\alpha$-admissible;}

(ii) there exists $x_{0} \in X$ such that $\alpha\left(x_{0}, f\left(x_{0}\right)\right) \geq 1$;

(iii) if $\left\{x_{n}\right\}$ is a sequence in $X$ such that $\alpha\left(x_{n}, x_{n+1}\right) \geq 1$ for all $n \in \mathbb{N}$ and $x_{n} \rightarrow x \in X$ as $n \rightarrow \infty$, then $\alpha\left(x_{n}, x\right) \geq 1$ for all $n \in \mathbb{N}$.

Then the fixed point problem of $f$ has a solution; that is, there exists $x^{*} \in X$ such that $x^{*}=f\left(x^{*}\right)$.

Proof. Following the proof of Theorem 10, we know that $\left\{x_{n}\right\}$ is a Cauchy sequence in the complete metric space $X$. Then, there exists $x^{*} \in X$ such that $x_{n} \rightarrow x^{*}$ as $n \rightarrow \infty$.

On the other hand, from (22) and hypothesis (iii), we have

$$
\alpha\left(x_{n}, x^{*}\right) \geq 1, \quad \forall n \in \mathbb{N}
$$

Now, using the triangular inequality, (9) and (30), we get

$$
\begin{aligned}
d\left(x^{*}, f\left(x^{*}\right)\right) & \leq d\left(x^{*}, x_{n+1}\right)+d\left(x_{n+1}, f\left(x^{*}\right)\right) \\
& =d\left(x^{*}, x_{n+1}\right)+d\left(f\left(x_{n}\right), f\left(x^{*}\right)\right) \\
& \leq d\left(x^{*}, x_{n+1}\right)+\alpha\left(x_{n}, x^{*}\right) d\left(f\left(x_{n}\right), f\left(x^{*}\right)\right) \\
& \leq d\left(x^{*}, x_{n+1}\right)+\lambda\left(x_{n}\right) d\left(x_{n}, x^{*}\right),
\end{aligned}
$$

for all $n \in \mathbb{N}$. According to the proof of Theorem 10, we obtain that $\lambda\left(x_{n}\right) \leq \lambda\left(x_{0}\right)$ for all $n \in \mathbb{N}$. Therefore, we have

$$
d\left(x^{*}, f\left(x^{*}\right)\right) \leq d\left(x^{*}, x_{n+1}\right)+\lambda\left(x_{0}\right) d\left(x_{n}, x^{*}\right)
$$

for all $n \in \mathbb{N}$. Letting $n \rightarrow \infty$ in above relation, we obtain that $d\left(x^{*}, f\left(x^{*}\right)\right)=0$; that is, $x^{*}=f\left(x^{*}\right)$. Therefore, the fixed point problem of $f$ has a solution. This completes the proof.

Example 13. Let $X=[0, \infty)$, and the metric $d: X \times X \rightarrow$ $[0, \infty)$ is defined by

$$
d(x, y)=|x-y|
$$

for all $x, y \in X$. Define $f: X \rightarrow X$ and $\alpha: X \times X \rightarrow[0, \infty)$ by

$$
\begin{gathered}
f(x)= \begin{cases}\frac{x}{5}, & x \in[0,1], \\
\frac{3 x-2}{2}, & x>1,\end{cases} \\
\alpha(x, y)= \begin{cases}2, & x, y \in[0,1] \\
0, & \text { otherwise. }\end{cases}
\end{gathered}
$$

We can prove that $f$ is an $\alpha$ - $\lambda$-contraction mapping, where $\lambda: X \rightarrow[0,1)$ is defined by $\lambda(x)=4 / 5$ for all $x \in X$ and $f$ is also $\alpha$-admissible. It is easy to see that there exist $x_{0}=$ $1 \in X$ such that $\alpha\left(x_{0}, f\left(x_{0}\right)\right)=\alpha(1, f(1))=\alpha(1,1 / 5)=1$. Moreover, condition (iii) in Theorem 12 holds. Therefore, all hypotheses of Theorem 12 hold and thus Theorem 12 assures the existence of fixed points of $f$ which are points 0 and 2 .

Remark 14. Theorem 10 cannot be used in case of Example 13 because $f$ is not continuous. Also, the Banach contraction principle cannot be used since $f$ does not satisfy Banach contractive condition.

We obtain that Theorems 10 and 12 do not claim the uniqueness of fixed point. To assure the uniqueness of the fixed point, we will consider the following hypotheses.

$\left(\mathrm{H}_{0}\right): \alpha(a, b) \geq 1$ for all fixed points $a, b$ of mapping $f$ : $X \rightarrow X$.

$\left(\mathrm{H}_{1}\right)$ : for all $x, y \in X$, there exists $z \in X$ such that $\alpha(x, z) \geq$ 1 and $\alpha(y, z) \geq 1$.

Theorem 15. Adding condition $\left(H_{0}\right)$ or $\left(H_{1}\right)$ to the hypotheses of Theorem 10 (resp., Theorem 12) we obtain uniqueness of the fixed point of $f$.

Proof. Suppose that $x^{*}$ and $y^{*}$ are two fixed points of $f$. If condition $\left(\mathrm{H}_{0}\right)$ holds, then we get the uniqueness of the fixed point of $f$ from (9). So we only show that the case of $\left(\mathrm{H}_{1}\right)$ holds. From condition $\left(\mathrm{H}_{1}\right)$, there exists $z \in X$ such that

$$
\alpha\left(x^{*}, z\right) \geq 1, \quad \alpha\left(y^{*}, z\right) \geq 1 .
$$

Since $f$ is $\alpha$-admissible, from (35), we get

$$
\alpha\left(x^{*}, f^{n}(z)\right) \geq 1, \quad \alpha\left(y^{*}, f^{n}(z)\right) \geq 1,
$$

for all $n \in \mathbb{N}$. From (36) and (9), we have

$$
\begin{aligned}
d\left(x^{*}, f^{n}(z)\right) & =d\left(f\left(x^{*}\right), f\left(f^{n-1}(z)\right)\right) \\
& \leq \alpha\left(x^{*}, f^{n-1}(z)\right) d\left(f\left(x^{*}\right), f\left(f^{n-1}(z)\right)\right) \\
& \leq \lambda\left(x^{*}\right) d\left(x^{*}, f^{n-1}(z)\right)
\end{aligned}
$$

for all $n \in \mathbb{N}$. Proceeding inductively, we get

$$
d\left(x^{*}, f^{n}(z)\right) \leq\left[\lambda\left(x^{*}\right)\right]^{n} d\left(x^{*}, z\right),
$$


for all $n \in \mathbb{N}$. Letting $n \rightarrow \infty$ in previous inequality, we get

$$
\lim _{n \rightarrow \infty} f^{n}(z)=x^{*} .
$$

Similarly, using (36) and (9), we get

$$
\lim _{n \rightarrow \infty} f^{n}(z)=y^{*} .
$$

By the uniqueness of the limit of a sequence $\left\{f^{n}(z)\right\}$, we have $x^{*}=y^{*}$. This finishes the proof.

Remark 16. Since a Banach contraction mapping is an $\alpha$ - $\lambda$ contraction mapping, the Banach contraction principle can be considered as a corollary of our main results.

\section{Ulam-Hyers Stability and Well-Posedness Results through the Fixed Point Problems}

First we give the notion of Ulam-Hyers stability and wellposedness in sense of a fixed point problem (see also [7]).

Definition 17. Let $(X, d)$ be a metric space and let $f: X \rightarrow X$ be a mapping. The fixed point problem

$$
x=f(x)
$$

is called Ulam-Hyers stable if and only if there exists $c>0$ such that, for each $\varepsilon>0$ and for each $w^{*} \in X$ called an $\varepsilon$ solution of the fixed point equation (41), that is, $w^{*}$ satisfies the inequality

$$
d\left(w^{*}, f\left(w^{*}\right)\right) \leq \varepsilon
$$

there exists a solution $x^{*} \in X$ of (41) such that

$$
d\left(x^{*}, w^{*}\right) \leq c \varepsilon .
$$

Definition 18. Let $(X, d)$ be a metric space and let $f: X \rightarrow X$ be a mapping. The fixed point problem of $f$ is said to be wellposed if it satisfies the following conditions:

(i) $f$ has a unique fixed point $x^{*}$ in $X$;

(ii) for any sequence $\left\{x_{n}\right\}$ in $X$ such that $\lim _{n \rightarrow \infty} d\left(x_{n}, f\left(x_{n}\right)\right)=0$, one has $\lim _{n \rightarrow \infty} d\left(x_{n}, x^{*}\right)=0$.

Theorem 19. Let $(X, d)$ be a complete metric space. Suppose that all the hypotheses of Theorem 15 hold. Then the following assertion holds:

(a) if $\alpha(a, b) \geq 1$ for all $\varepsilon$-solutions $a, b$ of the fixed point equation (41), then the fixed point problem is UlamHyers stable;

(b) if $\alpha\left(x^{*}, x_{n}\right) \geq 1$ for all $n \in \mathbb{N}$, where $x_{n} \in X$ with $\lim _{n \rightarrow \infty} d\left(x_{n}, f\left(x_{n}\right)\right)=0$ and $x^{*}$ is a fixed point of $f$, then the fixed point problem is well-posed.

Proof. According to the proof of Theorem 15, we know that $f$ has a unique fixed point and so let $x^{*}$ be a unique fixed point of $f$.
Here, we show that the fixed point problem of $f$ is UlamHyers stable under the hypothesis in (a). Let $\varepsilon>0$ and $w^{*} \in X$ be a solution of (42); that is,

$$
d\left(w^{*}, f\left(w^{*}\right)\right) \leq \varepsilon .
$$

It is obvious that the unique fixed point $x^{*}$ of $f$ is also a solution of (42). From hypothesis in (a), we get $\alpha\left(x^{*}, w^{*}\right) \geq 1$. Now we have

$$
\begin{aligned}
d\left(x^{*}, w^{*}\right) & =d\left(f\left(x^{*}\right), w^{*}\right) \\
& \leq d\left(f\left(x^{*}\right), f\left(w^{*}\right)\right)+d\left(f\left(w^{*}\right), w^{*}\right) \\
& \leq \alpha\left(x^{*}, w^{*}\right) d\left(f\left(x^{*}\right), f\left(w^{*}\right)\right)+\varepsilon \\
& \leq \lambda\left(x^{*}\right) d\left(x^{*}, w^{*}\right)+\varepsilon .
\end{aligned}
$$

This implies that

$$
d\left(x^{*}, w^{*}\right) \leq \frac{1}{1-\lambda\left(x^{*}\right)} \varepsilon .
$$

Consequently, the fixed point problem of $f$ is Ulam-Hyers stable.

Next, we prove that the fixed point problem of $f$ is wellposed under the assumption in (b). Let $\left\{x_{n}\right\}$ be a sequence in $X$ such that $\lim _{n \rightarrow \infty} d\left(x_{n}, f\left(x_{n}\right)\right)=0$. From assumption in (b), we get $\alpha\left(x^{*}, x_{n}\right) \geq 1$ for all $n \in \mathbb{N}$. Now, we obtain that

$$
\begin{aligned}
d\left(x^{*}, x_{n}\right) & \leq d\left(x^{*}, f\left(x_{n}\right)\right)+d\left(f\left(x_{n}\right), x_{n}\right) \\
& =d\left(f\left(x^{*}\right), f\left(x_{n}\right)\right)+d\left(f\left(x_{n}\right), x_{n}\right) \\
& \leq \alpha\left(x^{*}, x_{n}\right) d\left(x^{*}, x_{n}\right)+d\left(f\left(x_{n}\right), x_{n}\right) \\
& \leq \lambda\left(x^{*}\right) d\left(x^{*}, x_{n}\right)+d\left(f\left(x_{n}\right), x_{n}\right)
\end{aligned}
$$

for all $n \in \mathbb{N}$. This implies that

$$
d\left(x^{*}, x_{n}\right) \leq \frac{1}{1-\lambda\left(x^{*}\right)} d\left(f\left(x_{n}\right), x_{n}\right)
$$

for all $n \in \mathbb{N}$. Since $\lim _{n \rightarrow \infty} d\left(x_{n}, f\left(x_{n}\right)\right)=0$, we have $\lim _{n \rightarrow \infty} d\left(x_{n}, x^{*}\right)=0$ and so the fixed point problem is wellposed.

Interesting Problems. Consider the following.

(i) In Theorem 15, can we replace conditions $\left(\mathrm{H}_{0}\right)$ and $\left(\mathrm{H}_{1}\right)$ by other conditions or more general conditions?

(ii) In Theorem 19, can we drop some condition in (a) and (b)?

(iii) In Theorem 19, can we prove other types of stability of fixed point problem?

(iv) Can we extend the result in this paper to other spaces such as complex valued metric space, partial metric space, $b$-metric space, or circular metric space?

\section{Conflict of Interests}

The authors declare that they have no conflict of interests regarding the publication of this paper. 


\section{Acknowledgment}

The first author gratefully acknowledges the support from the Deanship of Scientific Research (DSR) at King Abdulaziz University (KAU) during this research. The second author would like to thank the Thailand Research Fund and Thammasat University for financial support, under Grant no. TRG5780013, during the preparation of this manuscript. Moreover, the authors thank the editors and referees for their insightful comments.

\section{References}

[1] S. M. Ulam, A Collection of Mathematical Problems, Interscience, New York, NY, USA, 1960.

[2] D. H. Hyers, "On the stability of the linear functional equation," Proceedings of the National Academy of Sciences of the United States of America, vol. 27, no. 4, pp. 222-224, 1941.

[3] M.-F. Bota, E. Karapınar, and O. Mleşniţe, "Ulam-Hyers stability results for fixed point problems via $\alpha$ - $\psi$-contractive mapping in (b)-metric space," Abstract and Applied Analysis, vol. 2013, Article ID 825293, 6 pages, 2013.

[4] M. F. Bota-Boriceanu and A. Petruşel, "Ulam-Hyers stability for operatorial equations," Analele Stiintifice ale Universitatii Al I Cuza din Iasi: Matematica, vol. 57, no. 1, pp. 65-74, 2011.

[5] V. L. Lazăr, "Ulam-Hyers stability for partial differential inclusions," Electronic Journal of Qualitative Theory of Differential Equations, vol. 21, pp. 1-19, 2012.

[6] I. A. Rus, "The theory of a metrical fixed point theorem: theoretical and applicative relevances," Fixed Point Theory, vol. 9, no. 2, pp. 541-559, 2008.

[7] I. A. Rus, "Remarks on Ulam stability of the operatorial equations," Fixed Point Theory, vol. 10, no. 2, pp. 305-320, 2009.

[8] F. A. Tişe and I. C. Tişe, "Ulam-Hyers-Rassias stability for set integral equations," Fixed Point Theory, vol. 13, no. 2, pp. 659$668,2012$.

[9] J. Brzdęk, J. Chudziak, and Z. Páles, "A fixed point approach to stability of functional equations," Nonlinear Analysis: Theory, Methods and Applications, vol. 74, no. 17, pp. 6728-6732, 2011.

[10] J. Brzdek and K. Ciepliski, "A fixed point approach to the stability of functional equations in non-Archimedean metric spaces," Nonlinear Analysis: Theory, Methods and Applications, vol. 74, no. 18, pp. 6861-6867, 2011.

[11] J. Brzdęk and K. Ciepliński, "A fixed point theorem and the Hyers-Ulam stability in non-Archimedean spaces," Journal of Mathematical Analysis and Applications, vol. 400, no. 1, pp. 6875, 2013.

[12] L. Cadariu, L. Gavruta, and P. Gavruta, "Fixed points and generalized Hyers-Ulam stability," Abstract Applied Analysis, vol. 2012, 10 pages, 2012.

[13] F. S. de Blasi and J. Myjak, "Sur la porosité de l'ensemble des contractions sans point fixe," Comptes Rendus des Séances de l'Académie des Sciences I: Mathématique, vol. 308, no. 2, pp. 5154, 1989.

[14] S. Reich and A. J. Zaslavski, "Well-posedness of fixed point problems," Far East Journal of Mathematical Sciences (FJMS), Special volume, part III, pp. 393-401, 2001.

[15] B. K. Lahiri and P. Das, "Well-posedness and porosity of a certain class of operators," Demonstratio Mathematica, vol. 38, no. 1, pp. 169-176, 2005.
[16] V. Popa, "Well-posedness of fixed point problem in orbitally complete metric spaces," Studii şi Cercetări Ştiinţifice. Seria Matematică, no. 16, pp. 209-214, 2006, Proceedings of ICMI 45.

[17] V. Popa, "Well posedness of fixed point problem in compact metric spaces," Bulletin Universităţii Petrol-Gaze din Ploieşti. Seria Matematică-Informatică-Fizică, vol. 60, no. 1, p. 14, 2008.

[18] B. Samet, C. Vetro, and P. Vetro, "Fixed point theorems for $\alpha-\psi$-contractive type mappings," Nonlinear Analysis: Theory, Methods \& Applications, vol. 75, no. 4, pp. 2154-2165, 2012.

[19] R. P. Agarwal, W. Sintunavarat, and P. Kumam, "PPF dependent fixed point theorems for an c-admissible non-self mapping in the Razumikhin class," Fixed Point Theory and Applications, vol. 2013, article 280, 2013.

[20] M. A. Alghamdi and E. Karapinar, "G-beta-psi contractive type mappings and related fixed point theorems," Journal of Inequalities and Applications, vol. 2013, article 70, 2013.

[21] N. Hussain, E. Karapınar, P. Salimi, and P. Vetro, "Fixed point results for $G^{m}$-Meir-Keeler contractive and $G-(\alpha, \psi)$ Meir-Keeler contractive mappings," Fixed Point Theory and Applications, vol. 2013, article 34, 2013.

[22] E. Karapnar and B. Samet, "Generalized $(\alpha-\psi)$ contractive type mappings and related fixed point theorems with applications," Abstract and Applied Analysis, vol. 2012, Article ID 793486, 17 pages, 2012.

[23] E. Karapinar and W. Sintunavarat, "The existence of an optimal approximate solution theorems for generalized $\alpha$-proximal contraction non-self mappings and applications," Fixed Point Theory and Applications, vol. 2013, article 323, 2013.

[24] M. A. Kutbi and W. Sintunavarat, "The existence of fixed point theorems via $w$-distance and $\alpha$-admissible mappings and applications," Abstract and Applied Analysis, vol. 2013, Article ID 165434, 8 pages, 2013.

[25] W. Sintunavarat, S. Plubtieng, and P. Katchang, "Fixed point result and applications on b-metric space endowed with an arbitrary binary relation," Fixed Point Theory and Applications, vol. 2013, article 296, 2013.

[26] M. U. Ali, T. Kamran, W. Sintunavarat, and P. Katchang, "Mizoguchi-Takahashi's fixed point theorem with $\alpha, \eta$ functions," Abstract and Applied Analysis, vol. 2013, Article ID 418798, 4 pages, 2013. 


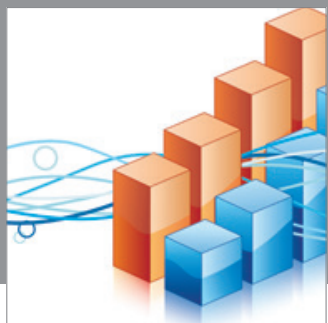

Advances in

Operations Research

mansans

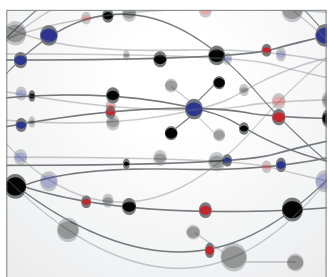

The Scientific World Journal
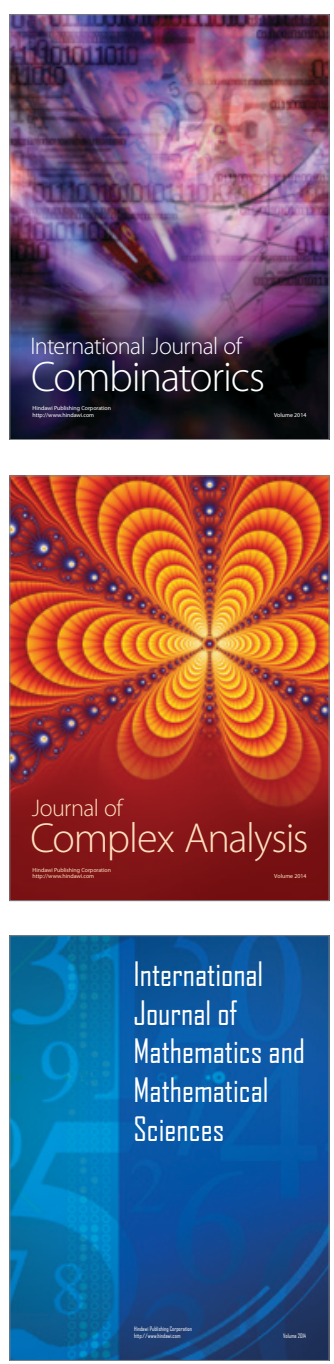
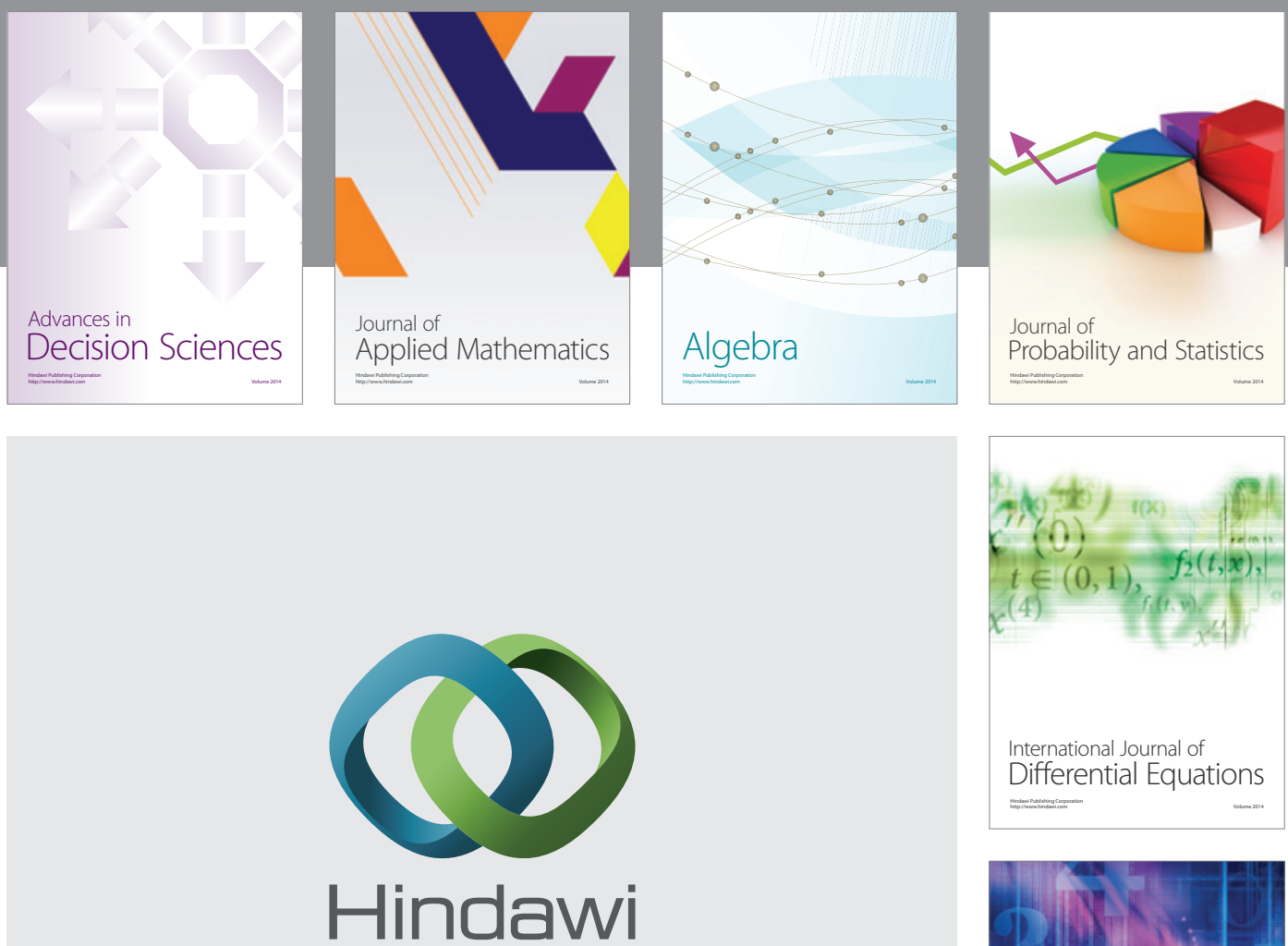

Submit your manuscripts at http://www.hindawi.com
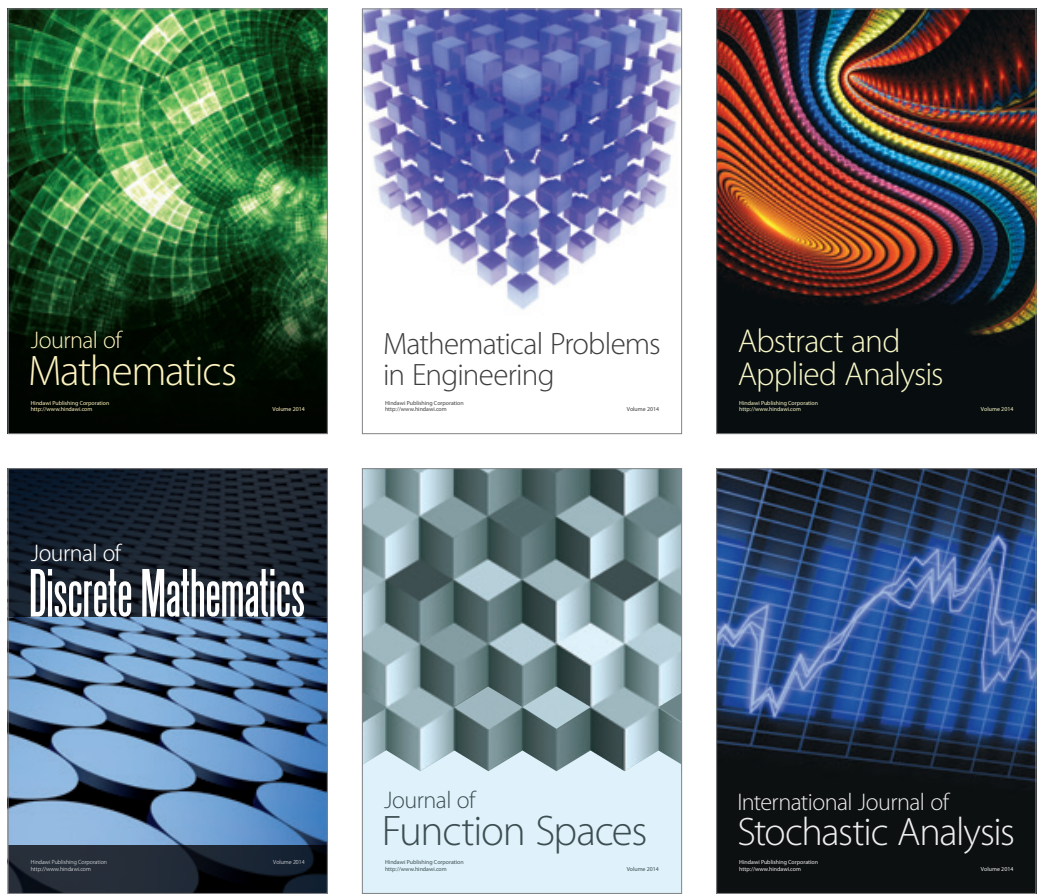

Journal of

Function Spaces

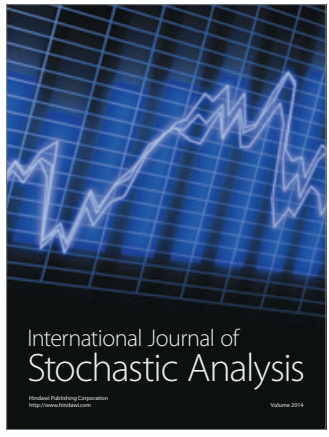

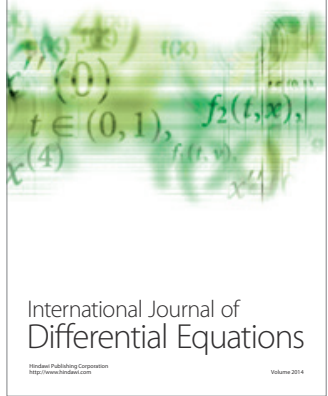
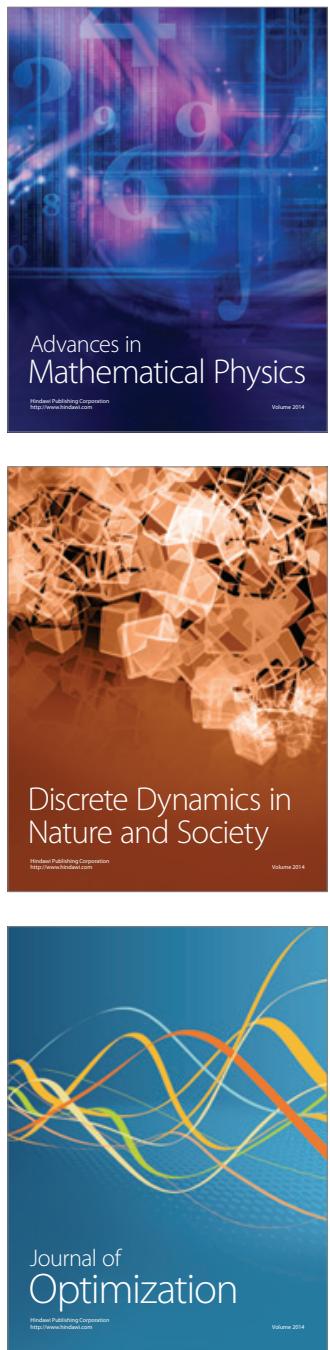